\title{
Presence of Phytol, a Precursor of Vitamin E in Chaetomorpha Antinnina
}

\author{
Byju $\mathrm{K}^{*}$, Vasundhara $\mathrm{G}^{\dagger}$, Anuradha $\mathrm{V}^{\ddagger}$, Nair $\mathrm{S} \mathrm{M}^{\S}$ and \\ N C Kumar*
}

\section{Abstract}

Phytol, a precursor of vitamin E was identified from green algae Chaetomorpha antinnina collected from Chullickal, Kochi Kerala coast, using GC-MS. Phytol is an acyclic diterpene alcohol that can be used as a precursor for the manufacture of synthetic forms of vitamin E and vitamin K1. The compound 3,7,11,15tetramethylhexadec-2-en-1-ol also known as phytol which exist naturally only in single isomeric form having molecular formula $\mathrm{C}_{20} \mathrm{H}_{40} \mathrm{O}$ and molecular mass 296 . From the total ion chromatogram more than twenty peaks were observed, the mass spectrum of the peak at Rt 21.53 was resolved and the major fragmentations were noted. Major fragmentation were $\mathrm{m} / \mathrm{z} 71$ the base peak, $\mathrm{m} / \mathrm{z} 296$ the molecular ion peak, m/z 43, m/z 57, m/z 81, m/z 95, and $\mathrm{m} / \mathrm{z} 123$. It was found that there are some other compounds apart from this identified phytol which are more complicated in structure and cannot be

* Inter University Centre for Development of Marine Biotechnology, Department of Chemical Oceanography, School of Marine Sciences, (IUCDMB, CUSAT), Cochin, India 682 016; byjuponnana@gmail.com

† (IUCDMB, CUSAT);drvasundharag@gmail.com

‡(IUCDMB, CUSAT);radhavattoni@gmail.com

$\S$ (IUCDMB, CUSAT);unnimurali@yahoo.com

** (IUCDMB, CUSAT); chandramohan.kumar@gmail.com 
characterised using GC-MS. Phytol is reported to have both antimicrobial and anticancer activities. The green algae Chaetomorpha antinnina can be proposed to be a good natural source for production of phytol.

Keywords: Phytol, Green algae, Chaetomorpha antinnina, Vitamin E, GC-MS.

\section{Introduction}

Seaweeds are the first marine organisms chemically analyzed, which describing 3,300 secondary metabolites from marine plants and algae, and they still remain an almost endless source of new bioactive compounds [1], They are known for their richness in polysaccharides, minerals and certain vitamins [2], but they also contain bioactive substances like proteins, lipids and polyphenols, with antibacterial, antiviral and antifungal properties, as well as many other biological properties (Kumar et al. 2008)[3].

Green algae range from simple, one-celled organisms to complex, multi-celled organisms. They may also live in large colonies. There are both marine and freshwater green algae species and similar to other algae, they are capable of photosynthesis. Chaetomorpha is a common and widespread green seaweed genus, characterized by unbranched filaments, typically grows on surf-exposed intertidal rocks, and the streamlined, unbranched filaments which might be an adaptation to such dynamic environments [4]. Molecular phylogenetic data indicate that Chaetomorpha forms a clade [5]. Only limited studies are done in Chaetomorpha antinnina about the composition of secondary metabolites. Premalatha et al 2011[6] investigated the antioxidant and antimicrobial potential of the Chaetomorpha antinnina and proved that it contains terpenes, phenolics, tannis, alkaloids and glycosides. These are the major secondary metabolites contributing to the antioxidant and antimicrobial properties of the sea weed extract, though the chemical characterisation of the extract is not done.

Diterpene, a type of terpene, is an organic compound composed of four isoprene units and has the molecular formula $\mathrm{C}_{20} \mathrm{H}_{32}$. They are derived from geranylgeranyl pyrophosphate. Diterpenes form the 58 
basis for biologically important compounds such as retinol, retinal, and phytol. They are known to be antimicrobial and antiinflammatory [7]. Phytol is a component of chlorophyll and vitamin $\mathrm{E}$ and $\mathrm{K}$. Vitamin $\mathrm{E}$ is an important nutritional supplement for humans and is obtained commercially by isolation from natural sources. Synthetic vitamin E is typically obtained by reacting trimethylhydroquinone with phytol in presence of acid catalyst, which is an important source than compared to the natural sources [8]. In this current scenario an effort is made to isolate phytol, a precursor of vitamin E from Chaetomorpha antinnina for considering it as a dietary source as well as a source of natural products - to be drug candidates.

\section{Experimental}

\subsection{General experimental procedure}

The solvents used were synthesis grade purchased from Merk Chemicals. GC- MS analysis was done using Perkin Elmer Clarus 680 GC-MS equipped with Head Space sampler. Column chromatography was done using silica gel 60-120 mesh size.

\subsection{Collection of seaweed}

The Green algae, Chaetomorpha antinnina collected from Chullickal, Kochi, Kerala during October 2012 was the study material used for the present investigation. The Green algae, Chaetomorpha antinnina were collected in glass bottle and brought to the shore, washed with fresh water free from detectable adhering other organisms, and preserved in methanol in a glass bottle. A large specimen with clear morphological features was separately preserved in ethanol in small glass container for identification purpose. The organisms (Figure 1) were brought to the laboratory for processing.

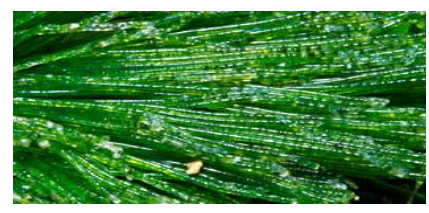




\subsection{Identification}

The Green algae were identified as Chaetomorpha antinnina, by Central Marine Fisheries Research Institute (CMFRI Cochin, Kerala). The voucher specimen (IUCDMB.R.No.4) of the green algae was preserved in the Inter University Centre for Development of Marine Biotechnology, Cochin University of Science And Technology.

\subsection{Extraction of active components}

The extraction of the dried, powered green algae Chaetomorpha antinnina $(10 \mathrm{~g})$ was carried out at room temperature with methanol for 4 days. The process of extraction was repeated until; negligible residue was left on removal of the solvent. The solvent was removed under reduced pressure. The residue was dissolved in minimum quantity of aqueous methanol. In an effort to further characterize the chemical constituents in the original sample, we fractionated the aqueous methanol sample by solvent partitioning with hexane. The hexane extracts were pooled, concentrated under vacuum and the hexane soluble portion was washed with water, dried over anhydrous $\mathrm{MgSO}_{4}$ and the solvents removed under reduced pressure. Column chromatography of the residue collected from hexane soluble fraction was done using silica gel with hexane: ethyl acetate on varying polarity. The fractions were collected and analysed by TLC and GC-MS. The fraction with $75 \%$ hexane was found to contain a mixture of several unidentified compounds and phytol.

\subsection{GC-MS Analysis}

Gas chromatographic analysis was done on Perkin Elmer Clarus 680 GC-MS equipped with headspace sampler. Helium was employed as carrier gas and the ionizing voltage was $70 \mathrm{eV}$. Oven temperature was programmed from $60^{\circ} \mathrm{C}$ to $290^{\circ} \mathrm{C}$ at $10^{\circ} \mathrm{C} \mathrm{min}-1$, for 15 minutes. Injector and detector temperature were kept constant at 280 and $290^{\circ} \mathrm{C}$, respectively. The column used was Elite 5 MS having $30 \mathrm{~m}$ length and $250 \mu \mathrm{m}$ id. Mass spectrum of each peak in the total ion chromatogram was resolved, and it was compared with NIST library spectra for the identification of the compounds. 


\section{Results and Discussion}

GC-MS analysis of the 75\% hexane fraction from Chaetomorpha antinnina revealed the presence of more than twenty compounds, from which phytol is characterized based on the mass spectrum obtained for the respective peak at Rt 21.53 minute (Figure 2). The mass spectrum of the compound was compared with those which are available in the NIST library (version 2.2) which describes more than three lakhs of compounds and its structure. It was found that the mass spectrum at Rt 21.53 was completely matched with phytol a diterpene alcohol. On the basis of the mass spectrum obtained, the major molecular ion fragmentations were identified and the compound is characterized (Figure 3). The $\mathrm{m} / \mathrm{z}$ value 71 was the maximum abundant one and which refers to the base peak. The molecular ion peak was at $\mathrm{m} / \mathrm{z} 296$ which tells about the molecular mass. The other fragments obtained were $\mathrm{m} / \mathrm{z} 43, \mathrm{~m} / \mathrm{z} 57, \mathrm{~m} / \mathrm{z} 81$, $\mathrm{m} / \mathrm{z}$ 95, m/z 111 and $\mathrm{m} / \mathrm{z} 123$. Major spectral peaks obtained during the fractionation of phytol are shown in Figure 4.

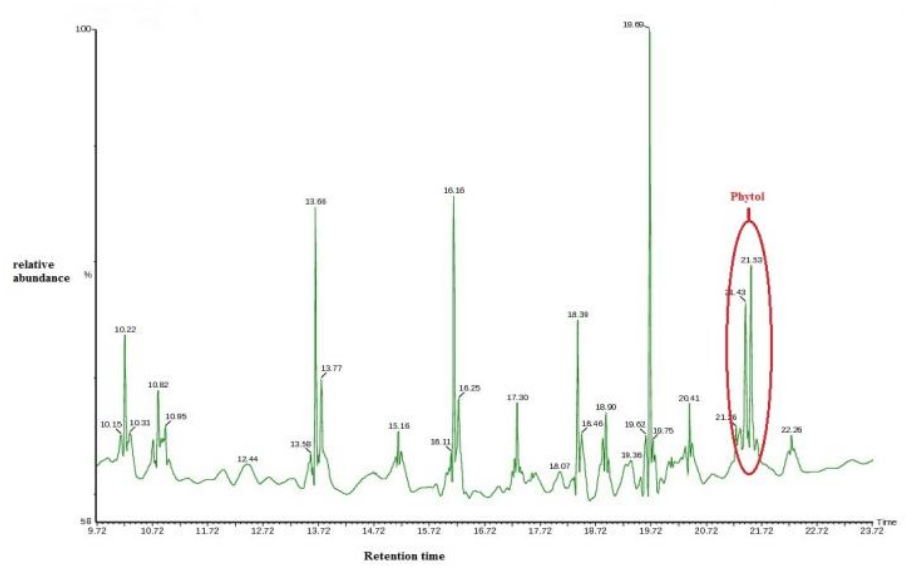

Figure 2: Total ion chromatogram of the fraction of $75 \%$ hexane extract from green algae, Chaetomorpha antinnina. 


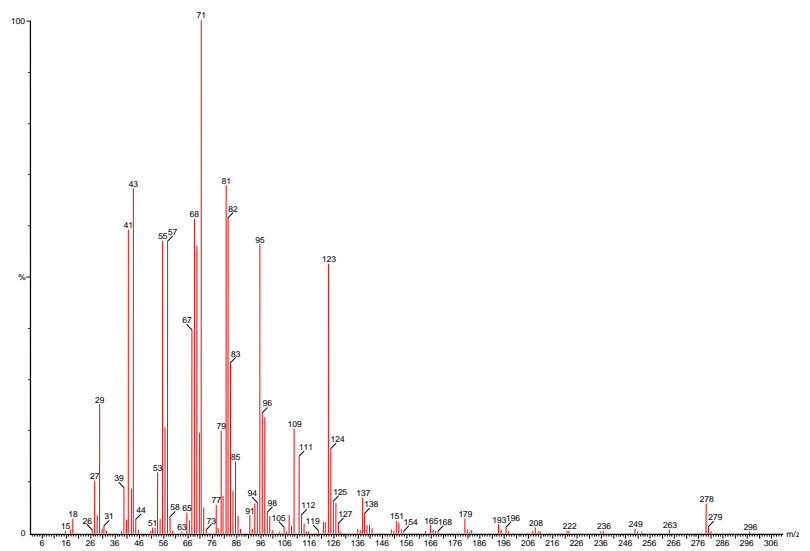

Figure 3: Mass spectrum of compound observed at Rt 21.53 minute

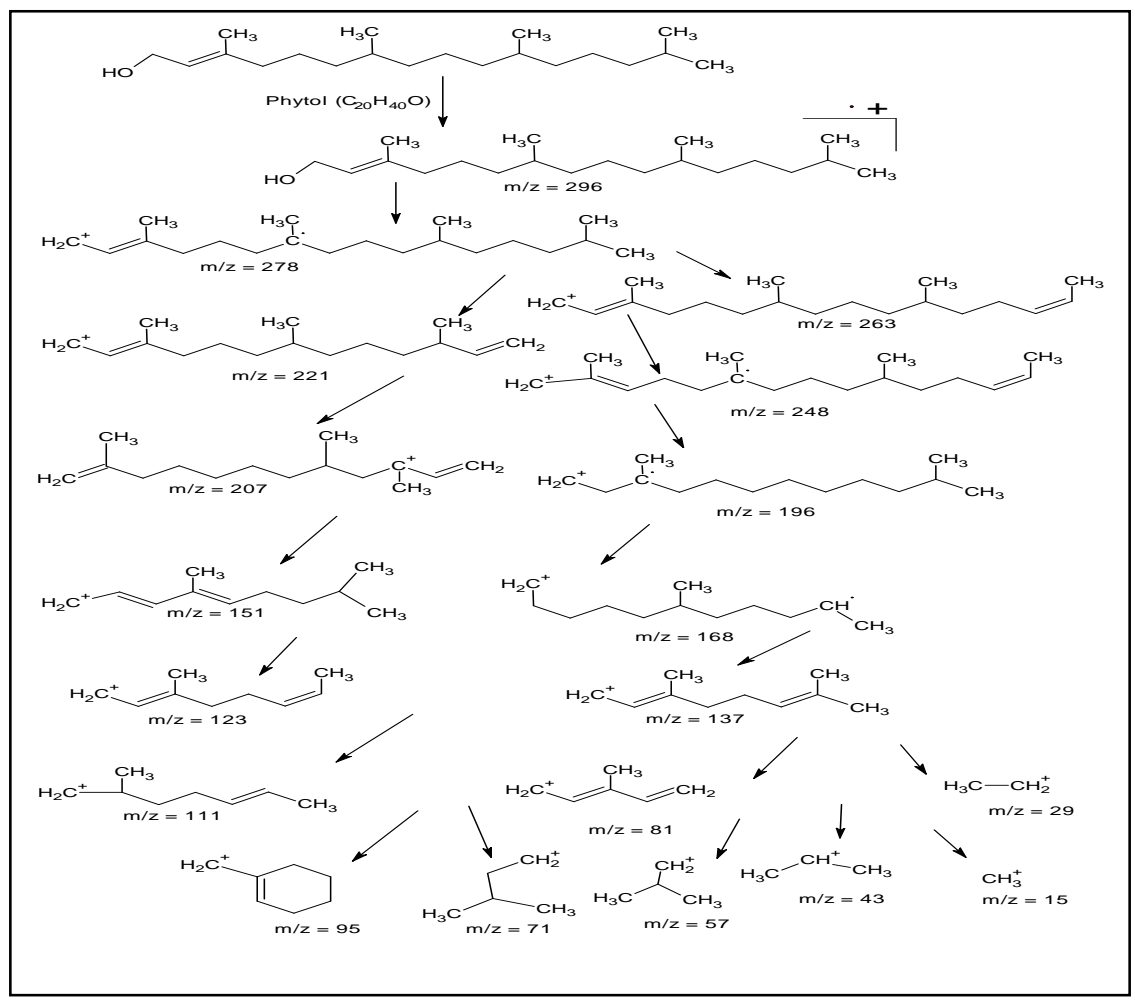

Figure 4: Major spectral peaks obtained during the fractionation of 3,7,11,15-tetramethylhexadec-2en-1-ol. 
Phytol has been reported to be found in various food forms and is a component of chlorophyll and vitamin E and K. Phytol is extracted from plants with high chlorophyll content or chemically derived through reactions starting from acetylene and acetone. Phytol provides pharmaceutical compositions for the prophylaxis, prevention and treatment of hypercholesterolemia, for lowering, controlling and maintaining normal levels of serum cholesterol, especially LDL cholesterol as well as related conditions such as obesity, insulin resistance, diabetes, atherosclerosis and related cardiovascular diseases [9]. Presence of phytol is reported from some of the plants which have been widely used as traditional Chinese medicines (TCMs) for a long time because of their pharmacological activity, low toxicity and costs [10]. It is also found in the ethanol extract of Murraya koenigii [11], in the essential oil of Elephantopus scaber, a famous medicinal herb from Yangjiang Country in Southern China [12], in the volatile fractions obtained from Rhaponticum acaule [13] and Hydrilla verticillata [14].

Chlorophyll is the most abundant photosynthetic pigment in plants. During senescence, a large fraction of chlorophyll is broken down giving rise to the accumulation of high amount of free phytol. The presence of the diterpene alcohol, phytol can be considered as common among plant volatiles, knowing that it is a hydrolysis product of the alcohol moiety of chlorophyll [15]. In addition to chlorophyll, another class of phytyl esters was also detected in plants, i.e. fatty acid phytyl esters [16,17]. Phytol is synthetically used for manufacturing a-tocopherol by reacting with trimetylhydroquinone in presence of acid catalyst. Thus identification of phytol is important in this theme as it is a precursor of vitamin E.

\section{Conclusion}

Identification of 3,7,11,15-tetramethylhexadec-2-en-1-ol(phytol) in the green algae Chaetomorpha antinnina is significant as it has tremendous pharmacological and industrial application as a dietary source of antioxidants. GC-MS analysis of 75\% hexane: ethyl acetate extract revealed the presence of plenty of volatile secondary metabolites which possesses complicated structure. The structural characterisation of 3,7,11,15-tetramethylhexadec-2-en-1ol(phytol) using the mass spectrum obtained for the pure peak at Rt 
21.53 is a precursor of vitamin E. More isolation studies are obligatory to discuss about the biosynthetic pathway and origin of phytol in Chaetomorpha antinnina.

\section{Acknowledgement}

Authors thank Central Marine Fisheries Research Institute (CMFRI Cochin, Kerala) which helped for the taxonomic identification of the green algae Chaetomorpha antinnina. The financial support received from the Government of Kerala to establish a new centre, Inter University Centre for Development of Marine Biotechnology (IUCDMB) is gratefully acknowledged.

\section{References}

[1] W. Fenical, "Chemical variation in a new bromochamigrene derivative from the red seaweed Laurencia pacifica," Phytochem. 15, 511-512, 1976. doi: 10.1016/S0031-9422(00)88959-1.

[2] S. Arasaki, and T. Arasaki, "Low calorie, high nutrition vegetables from the sea. To help you look and feel better", Tokyo: Japan Publications. pp. [1] 6-196. 1983.

[3] C. S. Kumar, P. Ganesan, P. V. Suresh and N. Bhaskar "Seaweeds as a source of nutritionally beneficial compounds-a review". J Food Sci Technol, 45, 1-13, (2008b).

[4] Frederik Leliaert, Sofie D'hondt, Lennert Tyberghein, Heroen Verbruggen and Olivier De Clerck "Atypical development of Chaetomorpha antennina in culture (Cladophorales, Chlorophyta)," Phycological Research, 59, 91-97, 2011 doi: 10.1111/j.14401835.2010.00604.x

[5] Leliaert F, Rueness J., Boedeker, C. et al. "Systematics of the marine microfilamentous green algae Uronema curvatum and Urospora microscopica (Chlorophyta)," Eur. J.Phycol. 44: 487-96, 2009. doi:10.1080/09670260903229540

[6] M. Premalatha, P. Dhasarathan. and P. Theriappan. "Phytochemical characterization and antimicrobial efficiency of seaweed samples, Ulva fasciata and Chaetomorpha antennina, "International Journal of Pharma and Bio Sciences 2, 288-293, 2011.

[7] http://en.wikipedia.org/ wiki/Diterpene, Retrieved on 30.032013. 
[8] Anthony John Hyatt, EP1095034A1, May 22001.

[9] Peter Olofsson, Malin Hultqvist and Rikard Holmdahl, "Phytol as a cholesterol lowering agent," Pub No.US2011/0015278A1, January 20, 2011.

[10] Yu L, Li X, Liu S, Xu G and Liang Y, "Comparative analysis of volatile constituents in Citrus Reticulata Blanco using GC-MS and alternative moving window factor analysis," J. Sep. Sci. 32, 3457 3465, 2009. doi:10.1002/jssc. 200900267

[11] R. Hema, S. Kumaravel and K. Alagusundaram. "GC/MS determination of bioactive components of Murraya koenigii." J. Am. Sci. 7, 80-83, 2011.

[12] L. Wang, S. Jian, P. Nan, J. Liu and Y. Zhong, "Chemical composition of the essential oil of Elephantopus scaber from southern China," Z. Naturforsch, 59, 327-329, 2004.

[13] O. Boussaada, S. Ammar, D. Saidana, J. Chriaa, I. Chraif, M. Daami, A. N. Helal and Z. Mighri "Chemical composition and antimicrobial activity of volatile components from capitula and aerial parts of Rhaponticum acaule DC growing wild in Tunisia" Microbiol. Res. 163, 87-95, 2008. doi:10.1016/j.micres.2007.02.010

[14] K. Byju, V. Anuradha, Emilda Rosmine, S. Muraleedharan Nair and N. Chandramohanakumar. "Chemical characterization of the lipophilic extract of Hydrilla verticillata: a widely spread aquatic weed," Journal of Plant Biochemistry and Biotechnology. September 2012. doi:10.1007/s13562-012-0159-5

[15] A. Radonic, I. Blazevic, J. Mastelic, M. Zekic, M. Skocibusic, Maravic " Phytochemical analysis and antimicrobial activity of Cardaria draba (L.) Desv. Volatiles," Chem Biodivers, 8, 1170-1181, 2011. doi:10.1002/cbdv.201000370

[16] G. W. Patterson, S. Hugly and D. Harrison, "Sterols and phytyl esters of Arabidopsis thaliana under normal and chilling temperatures," Phytochemistry, 33, 1381-1383, 1993. doi:10.1016/0031-9422(93)85095-9

[17] C. Peisker, T. Duggelin, D. Rentsch and P.Matile "Phytol and the breakdown of chlorophyll in senescent leaves," J Plant Physiol 135, 428-432, 1989 doi:10.1016/S0176-1617(89)80099-9 